\title{
MESSAGE OF THE PRESIDENT
}

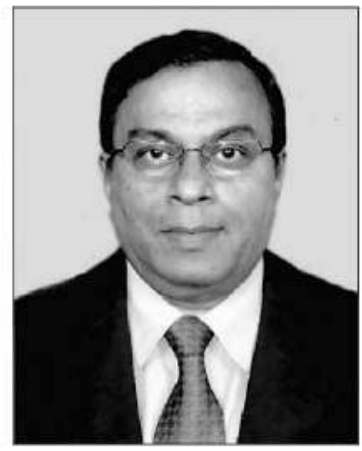

\section{Message on the occasion of Publication of Special issue of the Indian Welding Journal}

I am happy to know that the editorial board of the "Indian Welding Journal" has decided to bring out a special issue on the occasion of the International Welding Congress (IC 2014) at Pragati Maidan, New Delhi to be held between 9-11 April 2014. Our institute has the proud privilege of hosting two earlier International Congresses in 2005 and 2008 in Mumbai and Chennai respectively, but this is the first time that an international Congress is being staged in New Delhi. We also organized the $64^{\text {th }}$ International Welding Assembly and the International Conference in Chennai in 2011 and we should be able to maintain our success track.

The International Institute of Welding has been very active in its endeavor to disseminate the latest developments in the Welding science and technology all round the world, with particular emphasis on improving the quality of welded joint through development of processes and skill of welding personnel. The objectives of such regional congresses is primarily to bring together International Experts to share their experiences \& suggest approaches for achieving the above objectives in Welding Industries in India \& its neighboring countries .

For fulfilling the above objectives our institute also organizes an international Exhibition and I am happy that "Weld India 2014" the $8^{\text {th }}$ International Exhibition would also be held in the same venue between 10-12 April 2014. Such exhibitions help to bring together the welding world and the delegates and visitors get an update of the global progress in welding technology. Simultaneously, this time we have also decided to organize a plenary session on "Skill Development initiatives in India" to focus on the nationwide thrust in this area. I am sure the delegates attending the Congress would take this opportunity to exchange notes to draw a road map for the institute as well as for all welding professionals for the noble cause of Skill Development in Welding in keeping with the true spirit of our motto "Welding for Nation building"

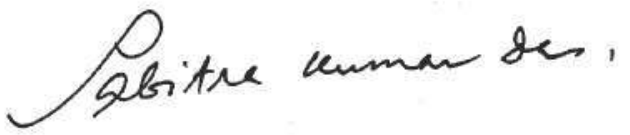

Pabitra Kumar Das

President

The Indian Institute of Welding 